\title{
Diabetes and abnormal glucose regulation in the adult population of Burkina Faso: prevalence and predictors
}

Tieba Millogo ${ }^{1,2^{*}}$ (D) Brice W. Bicaba ${ }^{1,3}$, Joseph Kouesyandé Soubeiga ${ }^{1,3}$, Estelle Dabiré ${ }^{3}$ Isaie Médah ${ }^{3}$ and Séni Kouanda ${ }^{1,2}$

\begin{abstract}
Background: The prevalence of diabetes mellitus (DM) is reportedly growing fast in sub-Saharan Africa. There is however a scarcity of epidemiologic data on DM in Burkina Faso. We carried out a secondary analysis of the first survey conducted in Burkina Faso on a nationally representative sample following the World Health Organization (WHO) Stepwise approach to risk factors Surveillance (STEPS) for non-communicable diseases (NCDs) with the aims of identifying the prevalence of NCDs and the prevalence of common risk factors for NCDs. We report here on the prevalence of diabetes and overall abnormal glucose regulation (AGR) and their associated risk factors.

Methods: In the primary study 4800 individuals were randomly sampled using a stratified multistage clusters sampling process. We used fasting capillary whole blood glucose level to define three glucose regulation statuses using WHO's cut-off levels: normal, diabetes and overall abnormal glucose regulation (impaired fasting glucose and diabetes). Appropriate statistical techniques for the analysis of survey data were used to identify the factors associated with diabetes and abnormal glucose regulation fitting a logistic regression model. Analyses were carried out using Stata Version 14 software.

Results: The prevalence of DM and AGR were respectively 5.8\% (95\% Cl: 5-6.7) and 9\% (95\% Cl: 8-10.1). Significant risk factors for $\mathrm{DM}$ include age $(\mathrm{OR}=1.9 ; P=0.009$ for the age group of 55-64), obesity (OR: 2.6; $P=0.001)$, former smoke (OR:2; $P=0.03)$, second-hand smoke (OR=1.7; $P=0.006)$ and total cholesterol level (OR: $2.1 ; P=0.024)$. The same predictors were also found significantly associated with AGR. In addition, having an history family diabetes was protective against $A G R(O R=0.5 ; P=0.032)$.

Conclusion: Diabetes is no longer a rare disease in the adult active population of Burkina Faso. Its burden is significant in both rural and urban areas. Health policies that promote healthy life style are needed to give precedence to the prevention in a context of an under-resourced country.
\end{abstract}

Keywords: Diabetes mellitus, Risk factors, Burkina Faso

\section{Background}

Diabetes mellitus (DM) is one of the major public health issue of the twenty-first century [1] bearing a heavy burden of morbidity and mortality worldwide [2-4]. It is now among the top ten leading causes of death globally [5] and the number of people affected in sub-Saharan

\footnotetext{
* Correspondence: millogorod@gmail.com; tmillogo@iasp-bf.org

'Institut Africain de Santé publique (IASP), Ouagadougou, 12 BP 199, Burkina Faso

${ }^{2}$ Institut de recherche en sciences de la santé (IRSS), Ouagadougou 0303 BP 7102, Burkina Faso

Full list of author information is available at the end of the article
}

Africa (SSA) is growing fast as compared to the other regions of the world [6]. Per World Health Organization $(\mathrm{WHO})$ s s estimates, the number of people living with diabetes will rise from 171 million in 2000 to 366 million in 2030 [7]. Every year, more than 1 million people die from diabetes and about 10 million develop disabilities and life-threatening complications [7]. Three out of four people with DM live in low-and-middle-income countries [3] and it is a contributing factor to heart diseases and stroke. The rising burden of DM is an important challenge for the health systems of SSA countries where 
the health care provision has been long shaped to battle against emergencies and outbreaks of infectious diseases [8]. The training of the health care workforce and the systems management of the health services in place are not always adapted to chronic conditions [9]. In the face of the emerging epidemic of DM, the World Health Assembly adopted the global strategy for integrated prevention of non-communicable diseases [10]. In 2011 the International Diabetes Federation (IDF) developed the first global plan against diabetes with a view of mobilizing and guiding initiatives against diabetes. These initiatives are based on global estimates of the disease burden including data from SSA $[2,3,6]$. Most of the key determinants of DM have also been well documented in the literature. These are: socioeconomic status, obesity, Physical inactivity and growing urbanization [11-17]. However, as an ill-prepared and a region with the highest growth rates of DM over the last decade, the situation in SSA Africa requests more attention and local and specific strategies drawn on real epidemiologic data are needed. Studies conducted in this region over the past 10 years showed important disparities between countries with reported burden of the disease ranking from very low prevalence to very high prevalence [6]. Life style related factors play an important role in the occurrence of DM. These are known to be highly context specific, making it also important to study the predictors of DM in each context. Very often Type 2 diabetes is preceded by a pre-diabetes status when it is still possible to initiate timely preventive interventions [18]. Despite the acknowledge that pre-diabetes patients are at high risk of developing DM and the benefits of risk stratification for preventives strategies [19-21], very few studies in LMIC have reported on overall abnormal glucose regulation (AGR) accounting for pre-diabetes status.

In Burkina Faso, data on DM are remarkably scarce and the available estimates were derived from data of neighbour countries ("within the same data region") that were deemed similar enough to provide accurate estimates [2]. With the recent availability of population level data obtained with the first survey on the prevalence of major risk factors for non-communicable diseases in Burkina Faso (Stepwise approach to Surveillance of chronic diseases), we aim at (i) determining the prevalence of DM and overall AGR and (ii) identifying their associated predictors in a nationally representative sample of the adult population of Burkina Faso.

\section{Methods}

\section{Study settings}

Burkina Faso is a landlocked country located in the heart of the west African region. Around half of its 18 million inhabitants live below the line of poverty and the majority of the population (77.30\%) live in rural areas [22].
The country faces a persistent high burden of diseases with a mix of endemic and epidemic diseases [23]. In recent years, a gradual increase in the burden of noncommunicable diseases has been observed [24] along with traditional infectious diseases such as malaria and meningitis. The prevalence of DM was estimated at 3\% in 2011.

\section{Study design and population}

We carried out a cross-sectional study that consisted of a secondary analysis of the STEPS survey data. The survey was carried out on a nationally representative sample of adults from September 26 to November 18, 2013.

The study participants were adults of both sex (men and women) residing in the country during the data collection period. Were considered in the survey individuals with the following criteria: age greater or equal to 25 years and less or equal to 64 years on the day of the survey and being resident in the country for at least the last six (06) months. People with important disabilities (serious mental disorder, hearing or intellectual disability) that affect their ability to answer the survey questions were excluded from the survey. An appointment was made if the selected person in the household was absent on the day of the survey. Selected individuals who remained absent after two (02) unsuccessful visits to the households were classified as refusal.

\section{Sampling and sample size calculation}

A stratified three-stage cluster sampling proportional to the size was used to select participants in the study. The enumeration areas (EAs) constructed from the 2006 general census of the population and housing (GCPH 2006) and updated in 2010 during the Demographic and Health Survey (DHS) in Burkina Faso serve as clusters. A full description of the EAs is available elsewhere [25]. The sample was stratified to ensure adequate representation of both rural and urban residential status. An excel spread sheet was used to draw the households to be surveyed from each selected cluster; at the third stage, the selection of individuals in households was made randomly using the Kish method [26]. In each household, one individual aged 25-64 years residing in the household was selected to participate in the survey. In the primary study the sample size calculation was based on the prevalence of hypertension as primary outcome. It was estimated that a minimum sample size of 4785 was required to measure the prevalence of hypertension with a precision of $5 \%$ with an anticipated prevalence of hypertension estimated at $29,4 \%$ and accounting for the design effect set at 1.5 and the subgroups analysis with 8 subgroups (4 age groups and 2 sex groups or rural vs urban groups). The non-response rate was anticipated to be $20 \%$. The minimum sample size was calculated using 
the following formulae: $n=\left(\frac{Z_{\alpha}^{2} * P(1-P)}{e^{2}} * 1.5 * 8\right) / 0.8$. The survey was conducted on a sample of 4800 persons and 4417 were finally included in our analysis. With this sample size and diabetes prevalence estimated at $4 \%$ in the unexposed group (general population) and an assumed increase risk of 1.5 times among exposed group, our study has $86.2 \%$ statistical power.

The data collection consisted in face-to-face interviews conducted using a standardized questionnaire adapted from WHO's STEPS surveys questionnaires. The questionnaires were implemented in Personal Digital Assistants (PDAs). Physical and biochemical measurements were carried out on the same day. Biochemical measurements comprised blood glucose level, cholesterol (total, LDL and HDL) and triglycerides levels and were conducted on fasting participants. A minimum of $8 \mathrm{~h}$ fasting was required and an appointment for the next day was made for participants that did not meet this criterion. Data collection was conducted by fieldworkers with medical training background (either medical student or nurses) supervised by a study medical doctor. Fieldworkers underwent a 5-days training including a field pretest of the study instruments prior to the commencement of the real survey.

\section{Study variables measurements and definitions}

The glucose level was measured using fasting capillary whole blood glucose level. All biochemical measurements were obtained using a portable device (CardioChek $P \bullet A^{\mathrm{mu}}$ SILVER) that performs the glucose, the cholesterol and triglycerides measurements using a whole blood sample obtained from a finger prick. This technique is analogous to the "point-of-care testing" widely used for the diagnosis and monitoring of diabetes $[27,28]$. The WHO cut-offs levels for capillary whole blood glucose were used to define different glucose regulation statuses (normal, abnormal and diabetes). A blood glucose level $<5.6 \mathrm{mmol} / \mathrm{l}(100 \mathrm{mg} / \mathrm{dl})$ was classified as normal glucose regulation. Participants with a blood glucose level $\geq 6.1 \mathrm{mmol} / \mathrm{l}(110 \mathrm{mg} / \mathrm{dl})$ or those that reported current use of anti-diabetic treatment were defined as having diabetes. Overall AGR status was defined by either having diabetes or having a blood glucose level $\geq 5.6 \mathrm{mmol} / \mathrm{l}(100 \mathrm{mg} / \mathrm{dl})$ [29]. The above cutpoints for diabetes and AGR are defined for whole blood glucose measurements. Recent published cut-points are based on plasma glucose measurements and are as following: normal $(\leq 6 \mathrm{mmol} / \mathrm{l})$, diabetes $(\geq 7 \mathrm{mmol} / \mathrm{l})$ and AGR (6.1-6.9 mmol/l) [30]. Whole blood measurements can be converted into plasma levels. Adding a converting factor of 1.1 to the whole blood glucose level to derive the equivalent plasma level was found reasonable [31]. This conversion is however subject to caution as the difference between the two measurements depends on the haematocrit and likely other personal characteristics [32]. The sensitivity analysis carried out using the cut-points for plasma glucose showed no significant difference in prevalence of diabetes using both types of cut-points. The prevalence of the overall AGR was however different using both types of cut-points. We reported both results in Fig. 1. Because equating glucose levels from one measuring procedure to another is subject to uncertainties and different converting factors are found in the literature [33], we only interpreted the results based on the cut-points for whole blood measurements.

The total cholesterol level was considered high if > $2 \mathrm{~g} / \mathrm{l}(5.2 \mathrm{mmol} / \mathrm{l})$. Socio-demographic and behavioural factors were also recorded: aside the socio-demographic characteristics (gender, age, marital status, educational status and occupation), the questionnaire covered smoking habits, alcohol use, dietary habits, and physical activity pattern. The WHO STEPS questionnaire is a validated questionnaire [34] that have been broadly in use in several settings for years. Second-hand smoke was defined by regular exposition to smoking in one's home or closed working place and former smoking referred to previous smokers who reported having quitted smoking.

Anthropometric measures recorded include the height, the weight and the waist. The height was measured in $\mathrm{cm}$ using a statometer on a subject without shoes and

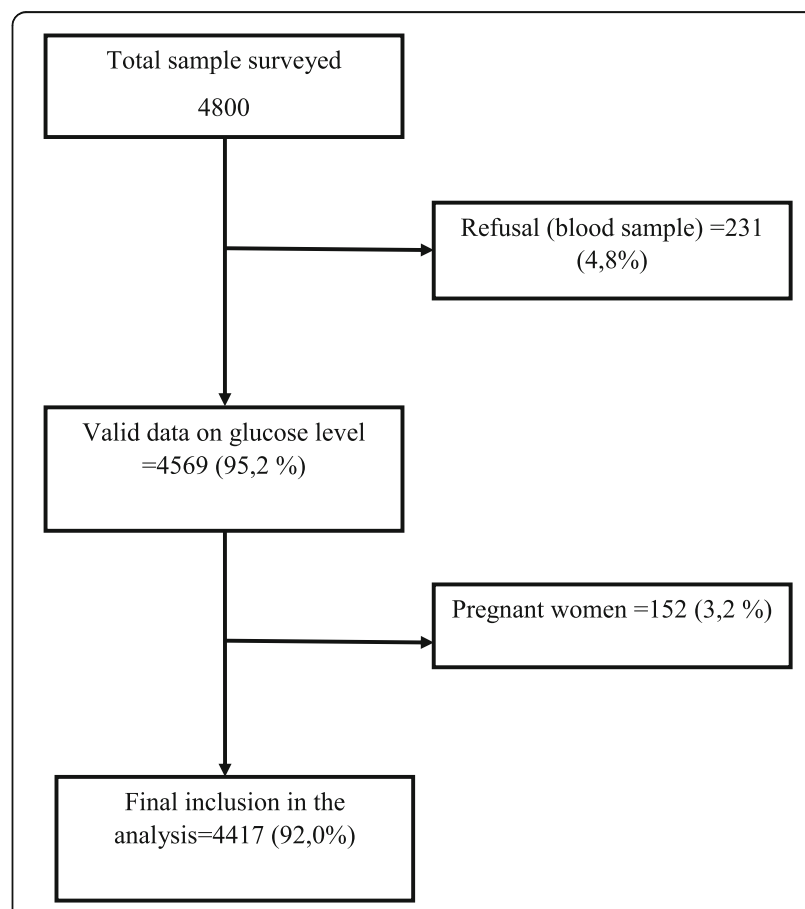

Fig. 1 Diagram flow of the study participants. As we analysed secondary data, this figure depicts the criteria that were applied in selecting the study participants and the numbers that were affected by these criteria 
the weight was measured in $\mathrm{kg}$ using a person scale on subject in light clothing and without shoes. The Body Mass Index (BMI) was calculated as weight (kg)/height2 (m) and was used as a measure of total body obesity while the waist circumference $(\mathrm{cm})$ was used as a marker of abdominal obesity. The BMI was considered normal if between 18.5 and 24.9, underweight if $<18.5$, overweight if between 25 and 29.9, and obese if $>30$. The waist circumference was considered: normal (less than $94 \mathrm{~cm}$ for men and less than $80 \mathrm{~cm}$ for women) or high (greater than or equal to $94 \mathrm{~cm}$ for men and higher than $80 \mathrm{~cm}$ for women).

\section{Statistical analysis}

The dependent variables were diabetes status and abnormal glucose regulation. All analyses were performed using Stata version 14.1. All the analyses were weighted based on the probability of each participant to be selected in the sample and based on complete cases analysis. We computed the standardized prevalence using direct standardization and WHO world standard population as standard population. We first re-calculated the percentages of the WHO world standard population that would have been in each age group if it was restricted to the age span (25-64) of our population. We then derived the standardized age specific prevalence by multiplying each age specific prevalence found in our population by the corresponding population proportion in the standard population. And we finally sum up the standardized age specific prevalence to get the overall standardized prevalence.

In univariate analysis, Chi-square tests and Fisher exact test were used for categorical covariates and independent two samples t-test for continuous covariates. We fitted a multivariable logistic regression model to determine the factors associated with diabetes and abnormal glucose regulation. Robust standard errors were computed to account for the clustered nature of the data. Epidemiologic relevance was used to select variables in the multivariable analysis. Nested models were compared using the Akaike's and Bayesian information criteria (AIC and BIC). The rule of parsimony was applied to choose the final model. Associations were considered significant if $p \leq 0.05$.

\section{Results}

\section{Background characteristics}

Out of the 4800 respondents, 231 (4.8\%) were excluded from the analysis because of refusal and missing data on blood glucose. Also152 women that were pregnant $(3.2 \%)$ at the time of the survey were excluded from the analysis (see Fig. 1). We analysed a total of 4417 individuals (92.0\%), among whom 2218 (52.7\%) were female. The age group 25-34 years was the most represented
$(40.7 \%)$ and a vast majority of the participants had never gone to school $(77.5 \%)$ and were married $(72.8 \%)$. The overall prevalence of obesity was $4.9 \%$ and 849 (19.9\%) had high blood pressure. Regarding family history of diabetes, $4.8 \%$ of respondents had a history of diabetes in the family. Further characteristics of the study sample and their distribution per glucose regulation status are summarized in Table 1.

\section{Prevalence of diabetes and AGR}

The overall prevalence of DM in our study was 5.8\% $\left(\mathrm{Cl}_{95 \%}\right.$ : 5-6.7). The lower prevalence was noted in the Cascades region with $1.3 \%$ while the highest pertained to the Centre region with $10.6 \%$ (result not shown). The prevalence of DM was higher in urban area $\left(8 \%\right.$; $\left(\mathrm{CI}_{95 \%}\right.$ : 6.1-10.4) as compared to rural area (5\%; $\left.\mathrm{CI}_{95 \%}: 4.2-6.0\right)$. Among all those that were classified diabetics, only 3,6\% previously knew their disease status before the survey. There was no statistically significant difference between the prevalence of $\mathrm{DM}$ in males $\left(6.3 \% ; \mathrm{CI}_{95 \%}\right.$ : 5.1-7.7) and females (5.4\%; $\mathrm{CI}_{95 \%}$ :4.4-6.7). The overall prevalence of AGR was 9\% $\left(\mathrm{CI}_{95 \%}: 8.0-10.1\right)$ and there was no significant difference between males and females $(9.7 \%$; $\mathrm{CI}_{95 \%}: 8.2-11.4$ vs $\left.8.3 \% ; \mathrm{CI}_{95 \%}: 7.1-9.8\right)$ and between urban and rural residents $\left(11.1 \%\right.$; $\mathrm{CI}_{95 \%}: 8.9-13.9$ vs $8.1 \%$; $\left.\mathrm{CI}_{95 \%}: 7.2-9.3\right)$. The distribution of the prevalence of DM and AGR per age groups and gender is presented in Fig. 2. In both sexes the prevalence of DM and AGR roughly increases with age. However, the increase is more marked in women after 54 years. The adjusted prevalence of DM and AGR using the WHO world standard population were respectively $6.1 \%\left(\mathrm{CI}_{95 \%}: 5.4-\right.$ $6.9)$ and $9.6 \%\left(\mathrm{CI}_{95 \%}: 8.7-10.5\right)$.

\section{Predictors of DM and AGR}

The results from the multivariate analysis are presented in Table 2.

Our analyses identified the following as significant risk factors for diabetes mellitus:

Age, with greater age exposing to greater risk of diabetes. As compared to 25-34 years old, being in the age groups of 45-54 years and 55-64 years increased someone's odds of having diabetes respectively 1.5 $(p=0.062)$ and $1.9(p=0.009)$ times. Obesity, as compared to normal, obese persons had more than twofold odds increased of having diabetes $(\mathrm{OR}=2.6$; $p=0.001$ ); Former smoke and second-hand smoke increased respectively 2 times $(\mathrm{OR}=2 ; p=0.03)$ and 1.7 times $(\mathrm{OR}=1.7 ; p=0.006)$ the odds of $\mathrm{DM}$ as compared to never smoke.

Elevated total cholesterol level was associated with increased odds of $\mathrm{DM}(\mathrm{OR}=2.1 ; p=0.024)$. The same predictors were also found significantly associated with AGR with the noticeable difference that persons with an 
Table 1 Background characteristics of study participants according to blood glucose regulation status

\begin{tabular}{|c|c|c|c|c|c|c|c|c|}
\hline & \multirow{2}{*}{\multicolumn{2}{|c|}{ All sample }} & \multicolumn{6}{|c|}{ Glucose regulation status } \\
\hline & & & \multicolumn{2}{|c|}{ Normal } & \multicolumn{2}{|c|}{ Have diabetes } & \multicolumn{2}{|c|}{ Have AGR ${ }^{a}$} \\
\hline & $n$ & $\%$ & $n$ & $\%$ & $\mathrm{n}$ & $\%(95 \% \mathrm{Cl})$ & $\mathrm{n}$ & $\%(95 \% \mathrm{Cl})$ \\
\hline \multicolumn{9}{|l|}{ Age groups } \\
\hline $25-34$ years & 1943 & 40.7 & 1817 & 93.4 & 80 & $4.5(3.5-5.8)$ & 126 & $6.6(5.4-8.0)$ \\
\hline $35-44$ years & 1124 & 27.9 & 1018 & 91.0 & 69 & $5.8(4.4-7.5)$ & 106 & $9.0(7.2-11.1)$ \\
\hline $45-54$ years & 819 & 19.4 & 736 & 89.5 & 50 & $6.9(5.0-9.5)$ & 83 & 10.5(8.2-13.4) \\
\hline $55-65$ years & 531 & 12.0 & 466 & 85.2 & 43 & $8.7(6.2-12.2)$ & 65 & 14.8(11.3-19.1) \\
\hline \multicolumn{9}{|l|}{ Gender } \\
\hline Male & 2199 & 47.3 & 2006 & 90.3 & 128 & $6.3(5.1-7.7)$ & 193 & $9.7(8.2-11.4)$ \\
\hline Female & 2218 & 52.7 & 2031 & 91.7 & 114 & $5.4(4.4-6.7)$ & 187 & 8.3(7.1-9.8) \\
\hline \multicolumn{9}{|l|}{ Education } \\
\hline None & 3418 & 77.5 & 3136 & 91.4 & 173 & $5.3(4.5-6.3)$ & 282 & 8.6(7.5-9.8) \\
\hline Primary & 680 & 15.1 & 618 & 90.4 & 46 & 7.6(5.4-10.6) & 62 & $9.6(7.2-12.8)$ \\
\hline Secondary & 212 & 5.1 & 187 & 87.4 & 16 & 7.9(4.5-13.4) & 25 & 12.6(7.9-19.5) \\
\hline Tertiary & 99 & 2.3 & 88 & 90.4 & 7 & $7.1(3.2-15.1)$ & 11 & $9.6(5.0-17.6)$ \\
\hline \multicolumn{9}{|l|}{ Residence } \\
\hline Urban & 963 & 27.2 & 860 & 88.9 & 72 & 8.0(6.1-9.4) & 103 & $11.1(8.9-13.9)$ \\
\hline Rural & 3454 & 72.8 & 3177 & 91.8 & 170 & $5.0(4.2-6.0)$ & 277 & $8.1(7.2-9.3)$ \\
\hline \multicolumn{9}{|l|}{ Marital Status } \\
\hline Single & 318 & 6.9 & 295 & 93.6 & 14 & $4.6(2.5-8.2)$ & 23 & $6.4(4.0-10.1)$ \\
\hline Married & 3793 & 87.0 & 3466 & 91.1 & 215 & $6.0(5.1-7.0)$ & 327 & 8.9(7.9-10.1) \\
\hline Divorced/Widow & 301 & 6.1 & 271 & 87.1 & 13 & $5.0(2.7-9.1)$ & 30 & 12.9(8.6-18.9) \\
\hline \multicolumn{9}{|l|}{ Smoking Status } \\
\hline Never & 2147 & 49.2 & 1981 & 92.6 & 97 & $4.4(3.5-5.5)$ & 166 & $7.4(6.2-8.8)$ \\
\hline Current Smoker & 901 & 19.6 & 825 & 90.6 & 50 & $6.0(4.4-8.2)$ & 76 & $9.4(7.3-12.2)$ \\
\hline Former Smoker & 141 & 2.8 & 118 & 83.5 & 15 & 10.6(6.0-18.1) & 23 & $16.5(10.6-24.7)$ \\
\hline Second Hand Smoking & 1227 & 28.4 & 1112 & 89.4 & 80 & $7.7(6.0-10.0)$ & 115 & 10.6(8.7-13.0) \\
\hline \multicolumn{9}{|l|}{ History of diabetes } \\
\hline No & 3484 & 79.3 & 3175 & 90.5 & 199 & $6.2(5.3-7.2)$ & 309 & $9.5(8.3-10.8)$ \\
\hline Yes & 204 & 4.8 & 190 & 93.8 & 11 & $4.7(2.3-9.2)$ & 14 & $6.2(3.4-11.2)$ \\
\hline Don't know & 729 & 15.9 & 672 & 92.7 & 32 & $4.5(3.0-6.6)$ & 57 & 7.3(5.5-9.8) \\
\hline \multicolumn{9}{|l|}{ HBP } \\
\hline No & 3568 & 80.1 & 3302 & 92.1 & 170 & $5.3(4.4-6.3)$ & 266 & 7.9(6.9-9.1) \\
\hline Yes & 849 & 19.9 & 735 & 86.8 & 72 & $8.2(6.3-10.5)$ & 114 & 13.2(10.7-16.2) \\
\hline \multicolumn{9}{|l|}{ Daily frut intake } \\
\hline$<5$ Portions & 4208 & 96.4 & 3867 & 91.7 & 221 & $5.4(4.6-6.3)$ & 341 & 8.3(7.4-9.4) \\
\hline$>=5$ Portions & 160 & 3.6 & 127 & 74.5 & 18 & $16.3(9.5-26.5)$ & 33 & $25.5(17.3-35.8)$ \\
\hline \multicolumn{9}{|l|}{ Waist circumference } \\
\hline Normal & 3773 & 83.8 & 3474 & 91.5 & 188 & $5.4(4.5-6.3)$ & 299 & $8.5(7.5-9.7)$ \\
\hline Elevated & 640 & 16.2 & 560 & 88.7 & 53 & $8.1(6.0-11.0)$ & 80 & 11.3(8.9-14.4) \\
\hline \multicolumn{9}{|l|}{ BMI } \\
\hline $18.5-25$ & 3135 & 69.5 & 2898 & 92.2 & 149 & $4.8(4.0-5.8)$ & 237 & $7.8(6.7-9.0)$ \\
\hline$<18.5$ & 498 & 11.9 & 449 & 88.5 & 27 & $6.5(4.1-10.2)$ & 49 & 11.5(8.3-15.7) \\
\hline$>25-29.9$ & 580 & 13.7 & 517 & 89.9 & 42 & $7.0(5.0-9.7)$ & 63 & $10.1(7.6-13.3)$ \\
\hline
\end{tabular}


Table 1 Background characteristics of study participants according to blood glucose regulation status (Continued)

\begin{tabular}{|c|c|c|c|c|c|c|c|c|}
\hline & \multirow{2}{*}{\multicolumn{2}{|c|}{ All sample }} & \multicolumn{6}{|c|}{ Glucose regulation status } \\
\hline & & & \multicolumn{2}{|c|}{ Normal } & \multicolumn{2}{|c|}{ Have diabetes } & \multicolumn{2}{|c|}{ Have $A_{G}{ }^{a}$} \\
\hline & $n$ & $\%$ & $n$ & $\%$ & $n$ & $\%(95 \% \mathrm{Cl})$ & $n$ & $\%(95 \% \mathrm{Cl})$ \\
\hline$>=30$ & 192 & 4.9 & 163 & 83.2 & 23 & $15.1(9.5-23.0)$ & 29 & $16.8(11.1-24.7)$ \\
\hline \multicolumn{9}{|l|}{ Total cholesterol } \\
\hline Normal & 4291 & 97.1 & 3937 & 91.4 & 224 & $5.5(4.8-6.5)$ & 354 & $8.6(7.6-9.6)$ \\
\hline Elevated & 124 & 2.9 & 98 & 76.6 & 18 & $15.5(9.3-24.7)$ & 26 & 23.4(15.2-34.2) \\
\hline \multicolumn{9}{|l|}{ Physical activity } \\
\hline Low & 648 & 18.1 & 581 & 89.0 & 49 & $8.2(6.0-11.2)$ & 67 & 11.0(8.4-14.2) \\
\hline Moderate & 1045 & 27.5 & 957 & 91.7 & 58 & $5.8(4.3-7.8)$ & 88 & $8.3(6.5-10.5)$ \\
\hline High & 2146 & 54.4 & 1958 & 90.7 & 114 & $5.6(4.5-6.9)$ & 188 & $9.3(7.9-11.0)$ \\
\hline \multicolumn{9}{|l|}{ Alcohol use } \\
\hline Never & 3036 & 68.7 & 2797 & 92.0 & 153 & $5.4(4.5-6.5)$ & 239 & $8.0(6.9-9.3)$ \\
\hline Every Day & 291 & 6.6 & 264 & 88.5 & 17 & $6.0(3.6-10.0)$ & 27 & 11.5(7.4-17.3) \\
\hline 3-6 Times per Week & 322 & 7.2 & 284 & 89.1 & 24 & $6.4(4.1-10.0)$ & 38 & 10.9(7.6-15.5) \\
\hline 1-2 Times per Week & 388 & 9.0 & 350 & 90.8 & 24 & $6.1(3.7-9.8)$ & 38 & $9.2(6.3-13.2)$ \\
\hline < 1 Day Per Week & 375 & 8.5 & 337 & 86.9 & 24 & $8.2(5.1-13.0)$ & 38 & 13.1(9.1-18.3) \\
\hline \multicolumn{6}{|c|}{ Standardized prevalence (using WHO world standard population) } & $6.1(5.4-6.9)$ & & 9.6(8.7-10.5) \\
\hline
\end{tabular}

${ }^{a} A G R$ Abnormal Glucose Regulation

history of DM in their family were $50 \%$ less likely to have an AGR $(\mathrm{OR}=0.5 ; p=0.032)$ as compared to those who didn't have such antecedent. As compared to normal BMI, underweight persons had also a $50 \%$ odds (0R $=1.5 ; p=0.041)$ increase of having an AGR.

\section{Discussion}

Diabetes mellitus is growing fast in SSA. Our study sought to provide current and valid epidemiological estimates from Burkina Faso. The prevalence of DM and AGR were respectively $5.8 \%$ and $9 \%$ in our study. There was no significant association between both glucose regulation statuses and gender. We found a rural versus urban significant difference for the prevalence of DM and not for the prevalence of overall AGR. Smoking status (former smoke and second-hand smoke), BMI (obesity), age (greater age) and total cholesterol (high level of total cholesterol) were significantly associated with and

\section{Prevalence of DM and AGR}

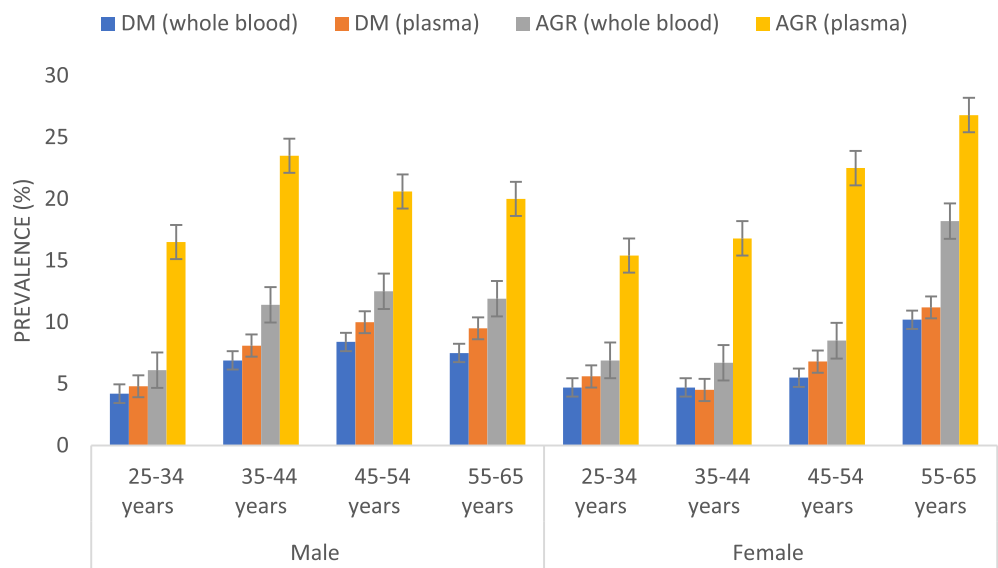

Fig. 2 Prevalence of DM and AGR per age groups and sex. We present in this figure the prevalence of diabetes mellitus and overall abnormal glucose regulation per age groups and stratified by gender using both types of cut-points: The cut-point for whole blood glucose measurement and the cut-point for plasma glucose measurement. $95 \% \mathrm{Cl}$ intervals were added to the figures 
Table 2 Risk factors for $\mathrm{DM}^{\mathrm{a}}$ and $\mathrm{AGR}^{\mathrm{b}}$ in multivariable analysis

\begin{tabular}{|c|c|c|c|c|c|c|c|c|c|c|c|c|}
\hline & \multicolumn{6}{|c|}{ Diabetes } & \multicolumn{6}{|l|}{ AGR } \\
\hline & \multicolumn{3}{|c|}{ Univariate analysis } & \multicolumn{3}{|c|}{ Mutivariable analysis } & \multicolumn{3}{|c|}{ Univariate analysis } & \multicolumn{3}{|c|}{ Mutivariable analysis } \\
\hline & $\overline{\mathrm{OR}^{c}}$ & $95 \% \mathrm{Cl}$ & $P$-value & $\overline{A O R^{d}}$ & $95 \% \mathrm{Cl}$ & $P$-value & $\overline{\mathrm{OR}}$ & $95 \% \mathrm{Cl}$ & $P$-value & $\overline{\mathrm{AOR}}$ & $95 \% \mathrm{Cl}$ & $P$-value \\
\hline \multicolumn{13}{|l|}{ Age groups } \\
\hline $25-34$ years & 1 & & & 1.0 & & & 1 & & & 1.0 & & \\
\hline $35-44$ years & 1.3 & $0.9-1.9$ & 0.203 & 1.2 & $0.8-1.9$ & 0.313 & $1.4^{*}$ & $1.0-1.9$ & 0.038 & 1.3 & $1.0-1.9$ & 0.086 \\
\hline $45-54$ years & $1.6^{*}$ & $1.0-2.4$ & 0.040 & 1.5 & $1.0-2.4$ & 0.062 & $1.7^{* *}$ & $1.2-2.4$ & 0.004 & $1.6^{*}$ & $1.1-2.3$ & 0.011 \\
\hline $55-65$ years & $2.0^{* *}$ & $1.3-3.2$ & 0.002 & $1.9^{* *}$ & $1.2-3.0$ & 0.009 & $2.5^{* * *}$ & $1.7-3.6$ & 0.000 & $2.3^{* * *}$ & $1.5-3.4$ & 0.000 \\
\hline \multicolumn{13}{|l|}{ Gender } \\
\hline Male & 1 & & & 1.0 & & & 1 & & & 1.0 & & \\
\hline Female & 0.9 & $0.6-1.2$ & 0.329 & 0.9 & $0.6-1.3$ & 0.548 & 0.8 & $0.7-1.1$ & 0.196 & 0.9 & $0.7-1.2$ & 0.401 \\
\hline \multicolumn{13}{|l|}{ History of diabetes } \\
\hline NO & 1 & & & 1.0 & & & 1 & & & 1.0 & & \\
\hline YES & 0.7 & $0.4-1.6$ & 0.443 & 0.5 & $0.3-1.1$ & 0.083 & 0.6 & $0.3-1.2$ & 0.174 & $0.5^{*}$ & $0.3-0.9$ & 0.032 \\
\hline Don't know & 0.7 & $0.5-1.1$ & 0.135 & 0.8 & $0.5-1.2$ & 0.263 & 0.8 & $0.5-1.1$ & 0.109 & 0.8 & $0.6-1.1$ & 0.211 \\
\hline \multicolumn{13}{|l|}{ Residence } \\
\hline Urban & 1 & & & 1.0 & & & 1 & & & 1.0 & & \\
\hline Rural & $0.6^{* *}$ & $0.4-0.9$ & 0.005 & 0.8 & $0.5-1.2$ & 0.303 & $0.7^{*}$ & $0.5-0.9$ & 0.020 & 0.8 & $0.6-1.2$ & 0.349 \\
\hline \multicolumn{13}{|l|}{ Education } \\
\hline None & 1 & & & 1.0 & & & 1 & & & 1.0 & & \\
\hline Primary & 1.5 & $1.0-2.2$ & 0.069 & 1.2 & $0.8-1.9$ & 0.298 & 1.1 & $0.8-1.6$ & 0.504 & 1.1 & $0.7-1.5$ & 0.728 \\
\hline Secondary & 1.5 & $0.8-2.8$ & 0.188 & 1.0 & $0.5-2.1$ & 0.957 & 1.5 & $0.9-2.6$ & 0.119 & 1.2 & $0.7-2.2$ & 0.517 \\
\hline Tertiary & 1.4 & $0.6-3.2$ & 0.482 & 0.9 & $0.4-2.4$ & 0.906 & 1.1 & $0.6-2.3$ & 0.738 & 0.9 & $0.4-2.0$ & 0.840 \\
\hline \multicolumn{13}{|l|}{ BMl } \\
\hline $18,5-25$ & 1 & & & 1.0 & & & 1 & & & 1.0 & & \\
\hline$<18,5$ & 1.4 & $0.8-2.3$ & 0.229 & 1.4 & $0.8-2.4$ & 0.214 & $1.5^{*}$ & $1.0-2.3$ & 0.030 & $1.5^{*}$ & $1.0-2.3$ & 0.041 \\
\hline$>25-29,9$ & 1.5 & $1.0-2.2$ & 0.063 & 1.3 & $0.8-2.1$ & 0.233 & 1.3 & $0.9-1.9$ & 0.107 & 1.2 & $0.8-1.7$ & 0.354 \\
\hline$>=30$ & $3.5^{* * *}$ & $2.0-6.1$ & 0.000 & $2.6^{* * *}$ & $1.5-4.7$ & 0.001 & $2.4^{* * *}$ & $1.5-4.0$ & 0.001 & $1.8^{*}$ & $1.1-3.1$ & 0.025 \\
\hline \multicolumn{13}{|l|}{ Smoking Status } \\
\hline Never & 1 & & & 1.0 & & & 1 & & & 1.0 & & \\
\hline Current Smoking & 1.4 & $0.9-2.1$ & 0.118 & 1.3 & $0.9-2.1$ & 0.198 & 1.3 & $0.9-1.8$ & 0.133 & 1.2 & $0.8-1.7$ & 0.400 \\
\hline Former Smoking & $2.6^{* *}$ & $1.3-5.0$ & 0.005 & $2.0^{*}$ & $1.1-3.9$ & 0.030 & $2.5^{* *}$ & $1.4-4.2$ & 0.001 & $2.0^{*}$ & $1.1-3.3$ & 0.013 \\
\hline Second Hand Smoking & $1.8^{* *}$ & $1.3-2.6$ & 0.001 & $1.7^{* *}$ & $1.2-2.4$ & 0.006 & $1.5^{* *}$ & $1.1-2.0$ & 0.009 & $1.4^{*}$ & $1.0-1.9$ & 0.030 \\
\hline \multicolumn{13}{|l|}{ Total cholesterol } \\
\hline Normal & 1 & & & 1.0 & & & 1 & & & 1.0 & & \\
\hline Elevated & $3.1^{* * *}$ & $1.7-5.7$ & 0.000 & $2.1^{*}$ & $1.1-4.0$ & 0.024 & $3.3^{* * *}$ & $1.9-5.6$ & 0.000 & $2.6^{* *}$ & $1.4-4.7$ & 0.002 \\
\hline
\end{tabular}

a Diabetes Mellitus

${ }^{\mathrm{b}}$ Abnormal Glucose Regulation

'Odds ratio

${ }^{\mathrm{d}}$ Adjusted OR

${ }^{*} p<0.05$

${ }^{* *} p<0.01$

${ }^{* * *} p<0.001$

increased odds of DM and AGR. The prevalence of DM in our findings is higher than that reported for Burkina Faso in the global estimates of diabetes by Whiting et al. [2] in 2011 (3.0\%). It's even higher than the projected level for the year 2030 in the same study (3.6\%). Our prevalence is however similar to the average prevalence for the whole Africa in the same study (5.9\%). Also, comparable to our result was that reported by Hilawe et al. [35] who found in a meta-analysis an average diabetes prevalence of 5.7 [95\% CI 4.8 to 6.8] in sub-Saharan 
Africa. Previous prevalence of DM in Burkina Faso was derived from either smaller size studies or from data pertaining to neighbour countries of Burkina Faso. To the best of our knowledge, our study is the first to report on a national representative sample. We found a difference between the rural and urban areas in the burden of DM, but this difference did not hold in multivariable analysis. The prevalence of overall AGR was similar between rural and urban residents suggesting finally that the burden of the disease may not truly differs between rural and urban areas. Findings of similar prevalence in rural and urban areas were reported by Baldé $\mathrm{N}$. et al. [12] in Guinea. However, these results contrast with that reported in other studies in Africa [11, 36] which showed a significantly higher prevalence in urban compared to rural area. The differences between studies may reflect true contextual differences in life styles (northern Africa vs western Africa). Albeit we saw differences in physical activity, fat intake, BMI and lipid profiles between urban and rural areas, it seems that both rural and urban residents are equally affected by the rising burden of diabetes in Burkina Faso.

\section{Factors associated with diabetes in Burkina Faso}

As for many NCDs, ageing is a risk factor for diabetes. The 45-54 and 55-64 years age groups were more likely to have diabetes compared to the age group of 2535 years. These results are similar to those reported in other studies conducted elsewhere [12, 24, 25].

The role of sex is however more controversial. Our study observed no relation between sex and both DM and AGR. Duboz et al. [14] in Senegal noted a risk 1.59 times higher in women $(P<0.05)$, while a meta-analysis of 36 cross-sectional studies found overall similar prevalence between both sexes (OR: 1.01, 95\% CI: 0.91 to 1.11) with however, regional specificities: higher prevalence among women in southern Africa, lower prevalence among women in East and Central Africa and in low- income sub-Saharan Africa [35].

The anthropometric and metabolic factors associated with diabetes in our study are BMI and total cholesterol. The role of these factors has been broadly reported. A meta-analysis conducted in 49 developing countries [6] noted that malnourished people with overweight or obesity were more exposed to getting diabetes than those with a normal BMI. Mayega et al. [16] in Uganda, Duboz et al. [14] in Sénégal also showed that overweight / obesity was a risk factor for diabetes. Total cholesterol is also a known biomarker associated with diabetes [37]. We believe that the prevalence of poor lipid profile along with the high prevalence of overweight / obesity $(18.6 \%)$ as well as eating habits will be important contributing factors to the increase in the prevalence of diabetes in the future. Former smoke and second-hand smoke were found to be significant predictors of DM and AGR in our study. The association between smoking status and DM was not confirmed in many studies. The difference may be due to these studies looking only at current and personal smoking. A smoker with fragile health status may quit smoking or urge to do so by health care workers making it difficult to find the association between current smoking and the disease. In opposite to some other studies [16-18], family history of diabetes was protective against DM and AGR in our study. The knowledge that one is at greater risk of DM may drive relatives of affected patients to have a healthier life style.

\section{Study limitations}

We report here the results of the first nationally representative survey on the prevalence and risk factors for diabetes in Burkina Faso. The study is however entitled to some limitations. The first limitation stems from the cross-sectional nature of the data that limits the possibility of deriving causal inferences. Glucose measurements were taken at only one occasion and could not be repeated as requested for the diagnosis of diabetes in the gold standards [38] and the device used performs whole blood glucose measurement instead of plasma glucose widely used in recent studies. The measurement of most exposures was based on the recall of respondents and some well-known risk factors for diabetes were not included in the study because data on these variables have not been collected during the STEPS survey. Part of such variables is the socio-economic status.

\section{Conclusion}

We report on the burden of diabetes and AGR and their associated risk factors in a nationally representative sample of the adult population in Burkina Faso. Our data showed an important burden of diabetes in Burkina Faso with urban and rural settings equally affected. Many risk factors identified in this study are modifiable. Appropriate health policies that promote healthy life style are thus needed to curb this disease which will be one of the main concerns in public health over the next 50 years worldwide.

\section{Abbreviations}

BMI: Body mass index; Cl: Confidence interval; EA: Enumeration area.; HBP: High Blood Pressure; HIV: Human Immunodeficiency Virus; NCD: NonCommunicable Diseases; PDA: Personal Digital Assistant; RGPH: General Census of Population and Housing; WHO: World Health Organization

\section{Acknowledgements}

The authors are grateful to the Ministry of Health for giving access to the data. We would also thank the African Institute of Public Health for the logistic support to the drafting of the article. 


\section{Funding}

This research was carried out by BB as partial fulfillment of his master program in public health at the African Institute of Public Health. BB was funded by the Ministry of Health of Burkina Faso for his master program. The Ministry of Health had no role in the design, the analysis, the interpretation of data and writing the manuscript.

\section{Availability of data and materials}

The dataset of the STEPS survey that was used in this research is available at the Ministry of Health upon request. Any request to reanalyze the data can be directed to Dr Brice Bicaba bicababrico78@gmail.com

\section{Authors' contributions}

MT and BB conceived the study. BB proposed an early draft of the paper. MT re-analysed the data to address reviewers' comments. MT, SKJ and SK made substantial contributions to the conception and design, analysis and interpretation of the data. ED and IM contributed significantly to management of the study throughout the data collection process and have been involved in revising it critically for important intellectual content. All authors read and approved the final manuscript.

\section{Ethics approval and consent to participate}

The protocol of the STEPS survey was reviewed and approved by the Ethics Committee for Health Research of the Ministry of Health, which gave clearance in accordance with regulations in force (Deliberation No. 2012-12092 of 05 December 2012). Written informed consent was systematically sought and obtained from all participants before inclusion in the study. For our research, we got a clearance from the General Directorate of Health to use the database of the STEPS survey (reference No. 2015/0231 / MS / DGS / DLM / PNMNT of February 12, 2015). The confidentiality of study participants was fully respected and the analyses performed did not identify any participant.

\section{Consent for publication}

Not applicable.

\section{Competing interests}

The authors declare that they have no competing interests.

\section{Publisher's Note}

Springer Nature remains neutral with regard to jurisdictional claims in published maps and institutional affiliations.

\section{Author details}

${ }^{1}$ Institut Africain de Santé publique (IASP), Ouagadougou, 12 BP 199, Burkina Faso. ${ }^{2}$ Institut de recherche en sciences de la santé (IRSS), Ouagadougou 03 03 BP 7102, Burkina Faso. ${ }^{3}$ Ministry of Health, Ouagadougou, Burkina Faso.

\section{Received: 15 May 2017 Accepted: 6 March 2018}

\section{Published online: 13 March 2018}

\section{References}

1. Klonoff DC. The increasing incidence of diabetes in the 21 st century. J Diabetes Sci Technol. 2009:3:1-2.

2. Whiting DR, Guariguata L, Weil C, Shaw J. IDF diabetes atlas: global estimates of the prevalence of diabetes for 2011 and 2030. Diabetes Res Clin Pract. 2011;94:311-21.

3. Wild S, Roglic G, Green A, Sicree R, King H. Global prevalence of diabetes: estimates for the year 2000 and projections for 2030. Diabetes Care. 2004; 27:1047-53.

4. Murray CJL, Vos T, Lozano R, Naghavi M, Flaxman AD, Michaud C, et al. Disability-adjusted life years (DALYS) for 291 diseases and injuries in 21 regions, 1990-2010: a systematic analysis for the global burden of disease study 2010. Lancet. 2012;380:2197-223.

5. WHO | The top 10 causes of death [Internet]. WHO. [cited 2017 Mar 11]. Available from: http://www.who.int/mediacentre/factsheets/fs310/en/

6. Liu L, Yin X, Morrissey S. Global variability in diabetes mellitus and its association with body weight and primary healthcare support in 49 lowand middle-income developing countries: global variability, diabetes mellitus, BMI and healthcare support. Diabet Med. 2012;29:995-1002.
7. Roglic G, World Health Organization, editors. Global report on diabetes. Geneva: World Health Organization; 2016.

8. Mbanya J-C, Mbanya D. Diabetes cost in sub-Saharan Africa. J Cardiovasc Risk. 2003:10:191-3.

9. Lamri L, Gripiotis E, Ferrario A. Diabetes in Algeria and challenges for health policy: a literature review of prevalence, cost, management and outcomes of diabetes and its complications. Glob Health. 2014;10:11.

10. World Health Organization. Global strategy for the prevention and control of noncommunicable diseases. [cited 2017 Mar 11]; Available from: http:// apps.who.int/gb/archive/pdf_files/EB105/ee42.pdf.

11. Balogun WO, Gureje O. Self-reported incident type 2 diabetes in the Ibadan study of ageing: relationship with urban residence and socioeconomic status. Gerontology. 2013;59:3-7.

12. Baldé N-M, Diallo I, Baldé M-D, Barry I-S, Kaba L, Diallo M-M, et al. Diabetes and impaired fasting glucose in rural and urban populations in Futa Jallon (Guinea): prevalence and associated risk factors. Diabetes Metab. 2007:33:114-20.

13. Connolly V, Unwin N, Sherriff P, Bilous R, Kelly W. Diabetes prevalence and socioeconomic status: a population based study showing increased prevalence of type 2 diabetes mellitus in deprived areas. J Epidemiol Community Health. 2000:54:173-7.

14. Duboz P, Chapuis-Lucciani N, Boëtsch G, Gueye L. Prevalence of diabetes and associated risk factors in a Senegalese urban (Dakar) population. Diabetes Metab. 2012;38:332-6.

15. Hodge AM, Flicker L, O'Dea K, English DR, Giles GG. Diabetes and ageing in the Melbourne collaborative cohort study (MCCS). Diabetes Res Clin Pract. 2013;100:398-403.

16. Mayega RW, Guwatudde D, Makumbi F, Nakwagala FN, Peterson S, Tomson $G$, et al. Diabetes and pre-diabetes among persons aged 35 to 60 years in eastern Uganda: prevalence and associated factors. PLoS One. 2013;8: e72554. Herder C, editor

17. Danquah I, Bedu-Addo G, Terpe K-J, Micah F, Amoako YA, Awuku YA, et al. Diabetes mellitus type 2 in urban Ghana: characteristics and associated factors. BMC Public Health. 2012;12.[cited 2017 Feb 14]. Available from: http:// bmcpublichealth.biomedcentral.com/articles/10.1186/1471-2458-12-210.

18. Peer N, Steyn K, Lombard C, Lambert EV, Vythilingum B, Levitt NS. Rising diabetes prevalence among urban-dwelling black south Africans. PLoS One. 2012;7:e43336. Herder C, editor

19. Chen K-T, Chen C-J, Gregg EW, Imperatore G, Narayan KMV. Impaired fasting glucose and risk of diabetes in Taiwan: follow-up over 3 years. Diabetes Res Clin Pract. 2003;60:177-82.

20. Coronado-Malagón M, Gómez-Vargas II, Espinoza-Peralta D, Arce-Salinas A. Progression toward type-2 diabetes mellitus among Mexican pre-diabetics. Assessment of a cohort. Gac Med Mex. 2009;145:269-72.

21. Meigs JB, Muller DC, Nathan DM, Blake DR. Andres R, Baltimore longitudinal study of aging. The natural history of progression from normal glucose tolerance to type 2 diabetes in the Baltimore longitudinal study of aging. Diabetes. 2003;52:1475-84

22. Institut National de la Statistique et de la Démographie (INSD) et ICF. Enquête Démographique et de Santé et à Indicateurs Multiples. 2012 [cited 2017 May 14]; Available from: http://www.burkinadoc.milecole.org/Pieces Jointes/PDFs/Conna\%C3\%AEtre_le_Burkina/Rep\%C3\%A8res_Statistiques/ Stat_burkinabf_eds_2010.pdf

23. Ministère de la Santé. Plan national de développement sanitaire (20112020) [Internet]. [cited 2017 Nov 3]. Available from: http://www. nationalplanningcycles.org/sites/default/files/country_docs/Burkina\%20Faso/ pnds_2011-2020_version_finale_adoptee_aout_2011_cm final.pdf.

24. Ministère de la Santé. Plan d'action de lutte contre les maladies non transmissibles (2013-2020).

25. Soubeiga JK, Millogo T, Bicaba BW, Doulougou B, Kouanda S. Prevalence and factors associated with hypertension in Burkina Faso: a countrywide cross-sectional study. BMC Public Health. 2017;17. [cited 2017 Mar 11]. Available from: http://bmcpublichealth.biomedcentral.com/articles/10.1186/ s12889-016-3926-8.

26. Wiegand H. Kish, L.: Survey sampling. John Wiley \&amp; sons, Inc., New York, London 1965, IX + 643 S., 31 Abb., 56 tab., Preis 83 s. Biom Z. 1968;10:88-9

27. Shibata K, Suzuki S, Sato J, Ohsawa I, Goto S, Iritani I, et al. Diagnostic accuracy of glycohemoglobin A1c ( $\mathrm{HbA1c}$ ) for postprandial hyperglycemia was equivalent to that of fasting blood glucose. J Clin Epidemiol. 2005;58:1052-7. 
28. Wood JR, Kaminski BM, Kollman C, Beck RW, Hall CA, Yun JP, et al. Accuracy and precision of the Axis-shield Afinion hemoglobin A1C measurement device. J Diabetes Sci Technol. 2012;6:380-6.

29. Alberti KGMM, Zimmet PZ, Consultation WHO. Definition, diagnosis and classification of diabetes mellitus and its complications. Part 1: diagnosis and classification of diabetes mellitus. Provisional report of a $\mathrm{WHO}$ consultation. Diabet Med. 1998;15:539-53.

30. World Health Organization, International Diabetes Federation. Definition and diagnosis of diabetes mellitus and intermediate hyperglycaemia: report of a WHO/IDF consultation [internet]. 2006 [cited 2017 Mar 11]. Available from: http://www.who.int/diabetes/publications/diagnosis\%5Fdiabetes2006/en/

31. D'Orazio P, Burnett RW, Fogh-Andersen N, Jacobs E, Kuwa K, Külpmann WR, et al. Approved IFCC recommendation on reporting results for blood glucose: International Federation of Clinical Chemistry and Laboratory Medicine Scientific Division, Working Group on Selective Electrodes and Point-of-Care Testing (IFCC-SD-WG-SEPOCT). Clinical Chemistry and Laboratory Medicine (CCLM) [Internet]. 2006;44. [cited 2017 Aug 16]. Available from: https://www.degruyter.com/view/j/cclm.2006.44.issue-12/ cclm.2006.275/cclm.2006.275.xml.

32. Stahl M, Brandslund I, Jørgensen LGM, Petersen PH, Borch-Johnsen K, Olivarius NDF. Can capillary whole blood glucose and venous plasma glucose measurements be used interchangeably in diagnosis of diabetes mellitus? Scand J Clin Lab Invest. 2002;62:159-66.

33. Colagiuri S, Sandbaek A, Carstensen B, Christensen J, Glumer C, Lauritzen T, et al. Comparability of venous and capillary glucose measurements in blood. Diabet Med. 2003;20:953-6.

34. WHO | STEPwise approach to surveillance (STEPS) [Internet]. WHO. [cited 2017 Mar 11]. Available from: http://www.who.int/chp/steps/en/.

35. Hilawe EH, Yatsuya H, Kawaguchi L, Aoyama A. Differences by sex in the prevalence of diabetes mellitus, impaired fasting glycaemia and impaired glucose tolerance in sub-Saharan Africa: a systematic review and metaanalysis. Bull World Health Organ. 2013;91:671-82D.

36. Bos M, Agyemang C. Prevalence and complications of diabetes mellitus in Northern Africa, a systematic review. BMC Public Health [Internet]. 2013;13. [cited 2017 Feb 14]. Available from: http://bmcpublichealth.biomedcentral. com/articles/10.1186/1471-2458-13-387.

37. Motala AA, Esterhuizen T, Gouws E, Pirie FJ, Omar MAK. Diabetes and othe disorders of Glycemia in a rural south African community: prevalence and associated risk factors. Diabetes Care. 2008:31:1783-8.

38. American Diabetes Association. Standards of medical care in diabetes-2010. Diabetes Care. 2010;33(Suppl 1):S11-61.

\section{Submit your next manuscript to BioMed Central and we will help you at every step:}

- We accept pre-submission inquiries

- Our selector tool helps you to find the most relevant journal

- We provide round the clock customer support

- Convenient online submission

- Thorough peer review

- Inclusion in PubMed and all major indexing services

- Maximum visibility for your research

Submit your manuscript at www.biomedcentral.com/submit 